\title{
Catalytic Static Mixer-Enabled Hydrogenation of a Key Fenebrutinib Intermediate: Real-time Analysis for a Stable and Scalable Process
}

\author{
René Lebl, ${ }^{\dagger} \ddagger$, Stephan Bachmann, ${ }^{\S}$ Paolo Tosatti, ${ }^{\S}$ Joerg Sedelmeier, ${ }^{\S}$ Kurt Püntener, ${ }^{\S}$ Jason D. \\ Williams, ${ }^{*}, \dot{\dagger}, \mathrm{C}$. Oliver Kappe $*, \dot{\dagger}, \dot{\dagger}$ \\ ${ }^{\dagger}$ Center for Continuous Flow Synthesis and Processing (CCFLOW), Research Center Pharmaceutical Engineering GmbH \\ (RCPE), Inffeldgasse 13, 8010 Graz, Austria \\ Institute of Chemistry, University of Graz, NAWI Graz, Heinrichstrasse 28, 8010 Graz, Austria \\ ${ }^{\S}$ Department of Process Chemistry \& Catalysis, F. Hoffmann-La Roche Ltd, 4070 Basel, Switzerland \\ KEYWORDS: flow chemistry, nitro hydrogenation, process analytical technology, catalytic static mixers, catalyst leaching
}

\begin{abstract}
Catalytic static mixer (CSM) technology is presented as an industrially-viable solution for an aromatic nitro group reduction in the synthesis of fenebrutinib. Factors effecting catalyst inhibition could be rapidly understood and mitigated by the use of real-time analytics (FT-IR, UHPLC). This facilitated the development of stable and optimal conditions in a system with 4 CSMs positioned inside a thermostated shell-and-tube reactor. Additional care was taken to ensure the control of three key impurities to low levels ( $<0.10$ area\% by offline UHPLC analysis). The optimal conditions $\left(0.4 \mathrm{M}\right.$ concentration, 20 bar, $120{ }^{\circ} \mathrm{C}, 3.3$ equiv $\left.\mathrm{H}_{2}\right)$ were then scaled up to a reactor with $8 \mathrm{CSMs}$, whereby an improvement in space-time yield was observed. Over $16 \mathrm{~h}$ of processing, a stable impurity profile was observed, without metal leaching. Finally, the reaction was performed in a system with 16 CSMs, which also provided an increase in space-time yield (to $26.2 \mathrm{~mol} / \mathrm{L} / \mathrm{h}$ or $6.5 \mathrm{~kg} / \mathrm{L} / \mathrm{h}$ ), resulting in $174 \mathrm{~g} / \mathrm{h}$ throughput, whilst maintaining an excellent impurity profile.
\end{abstract}

\section{INTRODUCTION}

Multiple sclerosis (MS) is a condition affecting the central nervous system, which can lead to paralysis and often significantly shortens life expectancy. MS affects around 2.5 million people worldwide and has no cure, but relies on various treatments to manage symptoms. ${ }^{1}$ Fenebrutinib $(\mathbf{1}, \text { Figure 1a })^{2}$ is a Bruton's tyrosine kinase (BTK) inhibitor, currently in phase III clinical trials for the treatment of MS. The synthesis of fenebrutinib is convergent, relying on a Suzuki-Miyaura coupling of two advanced fragments (Figure 1a). ${ }^{3}$ The upper fragment (highlighted in red) requires a nitro reduction of nitropyridine $\mathbf{2}$, to its corresponding aminopyridine $\mathbf{3}$, two synthetic steps away from the required boronic acid coupling partner (Figure 1b).

Although aromatic nitro reductions are common in the pharmaceutical and bulk chemical industries, they continue to present challenges for process development between lab and manufacturing scale for a number of reasons. ${ }^{4}$ These reactions are most often performed using hydrogen gas and a heterogeneous catalyst, resulting in a triphasic reaction system with scale-dependent mass transfer limitations. Many nitro hydrogenations are exothermic, so can be difficult to handle in large scale batch vessels, particularly due to their often rapid (mass transfer-limited) rate of reaction. ${ }^{5}$ Finally, batch processing often imposes to pressure and temperature limits, which acts as an additional barrier to achieving a productive process, whilst retaining a safe reaction profile.

Continuous processing has been well utilized for hydrogenation reactions for a number of years. ${ }^{6}$ This processing technique can allow safe handling of far higher reaction pressures and temperatures than in batch vessels, due to a smaller reactive inventory (limiting buildup of potentially explosive intermediates) and the absence of reactor headspace. Generally, continuous flow hydrogenation reactors make use of a heterogeneous catalyst immobilized within the reactor,

Figure 1. Structure of Fenebrutinib and Scheme Showing the Nitro Reduction of Interest.

(a)

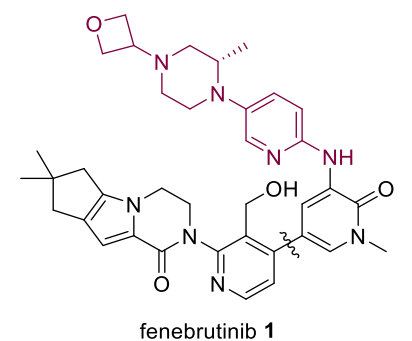

(b)

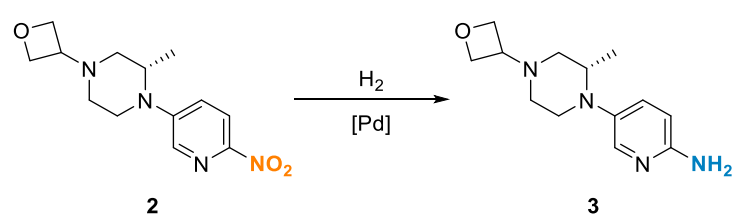

(a) Structure of fenebrutinib, showing the disconnection for the Suzuki-Miyaura coupling of two advanced intermediates. (b) Aromatic nitro reduction to be studied, two synthetic steps from the completed upper fragment. 
allowing a low effective catalyst loading (but high local catalyst loading), with no requirement for filtration of the reactor effluent.

Numerous catalyst technologies have been reported for use in continuous flow reactors. Arguably the simplest of these uses a packed bed of active catalyst, ${ }^{7}$ which often remains the method of choice in the pharmaceutical and other industries. ${ }^{8,9}$ However, this requires scale-dependent optimization of the catalyst particle sizing, to balance reactivity against pressure drop. Furthermore, significant efforts are also necessary to ensure reproducible catalyst packing and to avoid flow channeling. ${ }^{9}$ Other approaches include the use of metal foams, ${ }^{10}$ or polymer-based carbon supports. ${ }^{11}$

Another modern solution for immobilized catalysts is the use of catalytic static mixers (CSMs). ${ }^{12,13}$ These have been reported with a number of different coating methods, including electroplating, cold spray coating or slurry coating with $\mathrm{Pd} / \mathrm{Al}_{2} \mathrm{O}_{3}$. Previous studies using these catalysts report excellent catalyst stability with little to no leaching observed under experimental conditions. Furthermore, only minimal pressure drop is incurred through the use of these supports, implying that scaling up the reactor can be done by simply increasing the number of CSMs in series or parallel. ${ }^{14}$ Similar to other immobilized catalyst technologies for this class of reaction, catalyst deactivation over time has been observed and must be managed accordingly. ${ }^{12,13}$

Herein, we discuss the use of CSM technology for the effective hydrogenation of nitropyridine 2 . In order to observe and control any change in activity over time, a combined monitoring approach of inline FT-IR and online UHPLC was implemented. This approach facilitated the development of a stable process, where all of the key process impurities could be controlled, whilst achieving an exceptionally high reaction throughput.

\section{RESULTS AND DISCUSSION}

The hydrogenation of interest comes with multiple challenges, due to the formation of several troublesome impurities (Figure 2a). These include azo and azoxy intermediates (4 and $\mathbf{5}$, respectively), thought to arise from condensation of the nitroso and hydroxylamine intermediates (2a and $\mathbf{2 b}$ ). The combined level of these impurities must be tightly controlled and may not surpass 0.10 area\% by HPLC

Figure 2. Intermediates and Key Impurities in the Hydrogenation of Interest and Reaction/Analytics Setup.

(a)
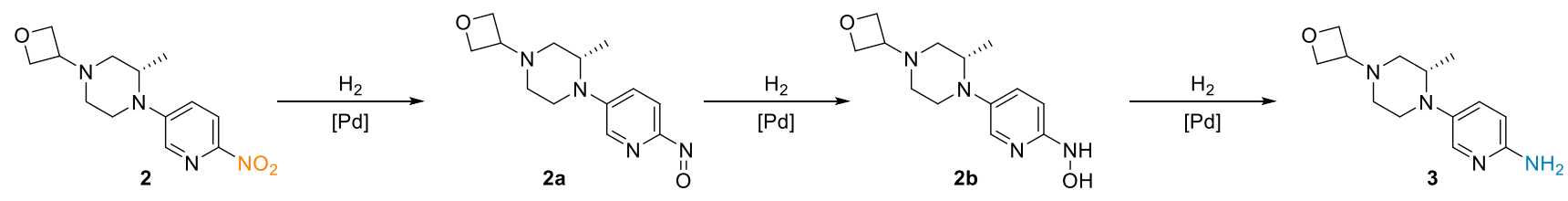

Key impurities:

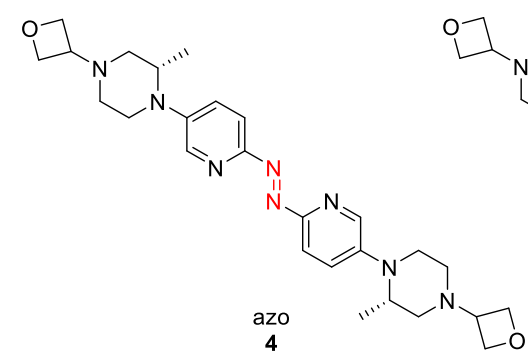

(b)

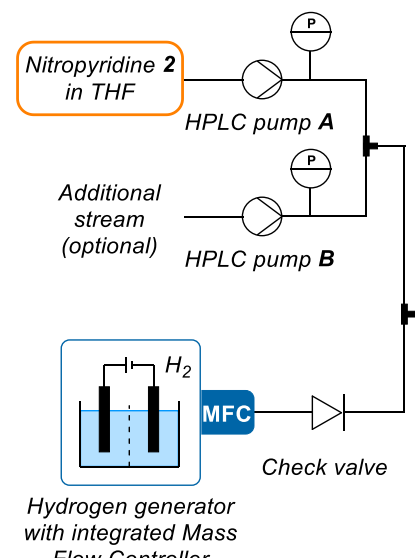

Flow

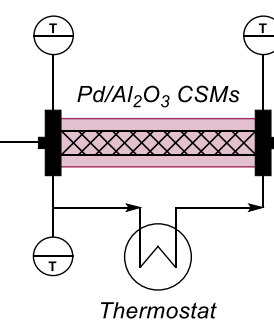

Thermostat
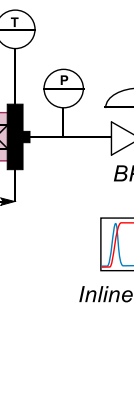

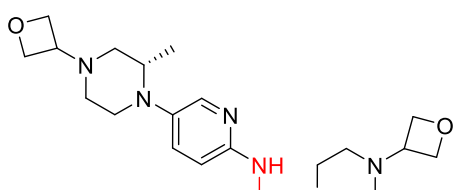

$\mathrm{H}_{2} \mathrm{~N}$

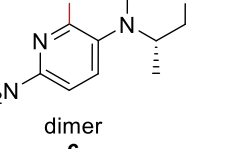

(c)

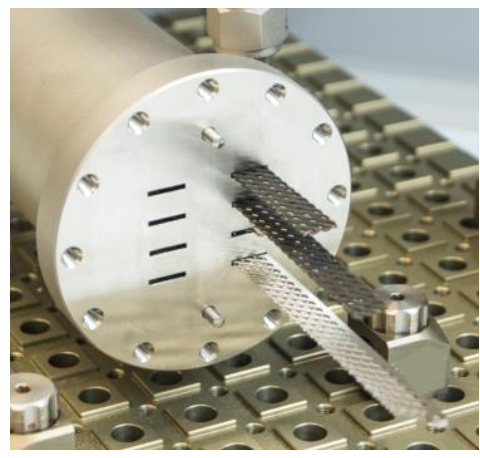

(a) Key impurities to be controlled in the hydrogenation process, arising from reactions of intermediate species. (b) Schematic representation of the experimental setup used to study this reaction, including real-time analysis by inline FT-IR and online UHPLC. P and T denote pressure and temperature sensors, respectively. (c) Photograph showing the open shell-and-tube reactor, with static mixers partially removed. 
assay, to ensure acceptable levels downstream. An additional dimeric impurity, $\mathbf{6}$ has been identified and should also be controlled below 0.10 area $\%$ in this step.

In order to investigate the reaction in detail, particularly with respect to stability of the process and CSM activity over time, a platform (based on an Ehrfeld Miprowa shell-and-tube reactor) featuring inline FT-IR and online UHPLC analysis was utilized (Figure 2b). ${ }^{15}$ This reactor setup also featured numerous temperature sensors, as well as pressure sensors before and after the reactor. A membrane-based back pressure regulator (BPR) was used to pressurize the reactor (Equilibar Zero Flow), combined with an electronic pressure meter (Bronkhorst ELPress) for automated control of the reaction pressure. The Miprowa reactor allows different configurations, whereby the number of CSMs can be varied. This feature was leveraged in the present study, to examine the behavior of the reaction on three different scales (4, 8 or 16 CSMs).

\section{Initial Reaction Optimization (4 CSMs)}

Initial optimization reactions were carried out using 4 (of a total 16 possible) CSMs. The Pd-electroplated CSMs displayed only a minimal extent of reaction $(\sim 6 \%$ conversion, see Supporting Information, section 2.2.1.), whilst $\mathrm{Pd} / \mathrm{Al}_{2} \mathrm{O}_{3}$ slurry coated CSMs were substantially more effective under the same conditions (full conversion). ${ }^{12,13}$ This can likely be attributed to the significantly higher effective surface area of the $\mathrm{Pd} / \mathrm{Al}_{2} \mathrm{O}_{3}$ variant (active surface area $=200 \mathrm{~m}^{2} / \mathrm{g}$, pore volume $=0.725 \mathrm{~mL} / \mathrm{g}$, average pore size $=14.45 \mathrm{~nm}),{ }^{12 \mathrm{~d}}$ which provides a large catalyst surface for reaction.

For all experiments, real-time monitoring by FT-IR and UHPLC was carried out to give an overall view of reaction progress over time. For a more detailed impurity analysis by UHPLC (impurities reported down to 0.025 area\%), offline samples were taken. These additional details for each experiment can be found in the Supporting Information. By inline FT-IR, it was possible to distinguish starting material 2 (N-O stretch, $\left.1570 \mathrm{~cm}^{-1}\right)$ and product $3\left(\mathrm{C}-\mathrm{N}\right.$ stretch, $1487 \mathrm{~cm}^{-}$ $\left.{ }^{1}\right)$. Additionally, the total analyte concentration $(2+3)$ could be estimated by an aromatic signal, which was present in both species $\left(\mathrm{C}-\mathrm{H}\right.$ bend, $\left.973 \mathrm{~cm}^{-1}\right)$, as well as the quantity of water $\left(1631 \mathrm{~cm}^{-1}\right)$, which is generated as a reaction by-product $(2$ equiv).

To obtain an initial picture of the reaction behavior at different residence times, the substrate $\mathbf{2}$ flow rate was increased from 1 to $5 \mathrm{~mL} / \mathrm{min}$, whilst maintaining all other process parameters (concentration $=0.2 \mathrm{M}$, pressure $=20 \mathrm{bar}$, jacket temperature $=80^{\circ} \mathrm{C}$, Figure 3a). Here, real-time analysis provided invaluable additional insight on behavior over time, which would have likely not been detected if standard offline measurements were used.

It was found that increasing the flow rate from 1 to $2 \mathrm{~mL} / \mathrm{min}$ already resulted in incomplete conversion of nitropyridine starting material 2. Furthermore, the conversion appeared to decrease over the $30 \mathrm{~min}$ at which these conditions were applied. This effect was increasingly apparent at higher flow rates $(3,4$ and $5 \mathrm{~mL} / \mathrm{min})$, which appeared to show a decrease in conversion at a constant gradient. Finally, to verify whether the initial conditions would still be stable, the flow rate was returned to $1 \mathrm{~mL} / \mathrm{min}$, where complete substrate conversion was no longer observed ( $\sim 95 \%$ conversion). A similar decrease in performance over time has been observed previously, when using this type of CSM. ${ }^{13}$ The problem was attributed to catalyst inhibition over time by reaction species, but was previously tackled by using a protic solvent and increasing the reaction temperature.

Figure 3. Real-time Analysis of Initial Parameter Screening Experiments

(a)

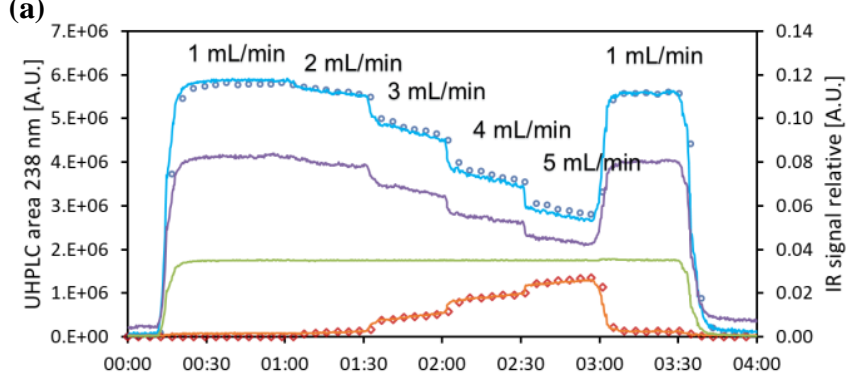

(b)
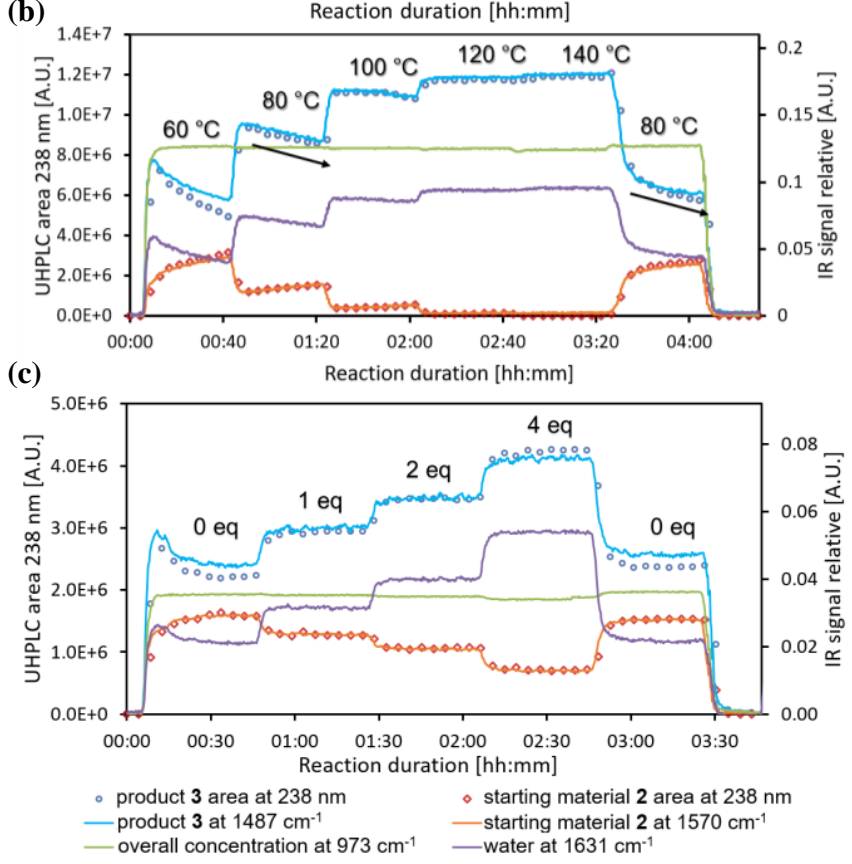

Initial parameter screening, monitored by FT-IR (colored lines, every $15 \mathrm{~s}$ ) and UHPLC (colored points, every $4.25 \mathrm{~min}$ ). (a) Liquid flow rate screening. Concentration $=0.2 \mathrm{M}$, pressure $=20$ bar, jacket temperature $=80^{\circ} \mathrm{C}$. (b) Jacket temperature screening. Concentration $=0.4 \mathrm{M}$, pressure $=20 \mathrm{bar}$, flow rate $=2 \mathrm{~mL} / \mathrm{min}$. (c) Water content screening. Concentration $=0.2 \mathrm{M}$, pressure $=20$ bar, jacket temperature $=80^{\circ} \mathrm{C}$, liquid flow rate $=2 \mathrm{~mL} / \mathrm{min}$.

Accordingly, in a second set of experiments, the jacket temperature was increased from 60 to $140{ }^{\circ} \mathrm{C}$ in steps of $20^{\circ} \mathrm{C}$, to determine its influence on reaction rate and stability (Figure $3 \mathbf{b}$ ). Temperature appeared to have a significant positive influence on the reaction, in both conversion and in decreasing its erosion over time. The gradient of conversion loss was substantially shallower at $80{ }^{\circ} \mathrm{C}$ compared to $60{ }^{\circ} \mathrm{C}$ and was not observed at all at $120^{\circ} \mathrm{C}$. Similarly to in the previous experiment, the final set of conditions were a replicate of the initial conditions, to determine whether any change had occurred over the duration. A substantial difference was observed between the two instances ( $78 \%$ conversion before vs $56 \%$ conversion after), implying that some loss of performance was also occurring even at higher temperature and would have an effect in longer term processing. 
The approach of adding a protic solvent was also examined, by first adding methanol as a co-solvent. Unfortunately, the reactivity and impurity profile were drastically affected by this modification (see Supporting Information, section 2.2.5.), suggesting that it would not be a viable solution. Since water (2 equiv) is generated as a by-product of this reaction (see FT-IR traces in Figure 3), it was anticipated that its presence would not be detrimental to reaction performance. Therefore, this hypothesis was tested further by adding small quantities of water to the reaction solution. Using a second HPLC pump, 1 to 4 equiv were introduced with the reaction stream (Figure 3c). Gratifyingly, the presence of water appeared to significantly improve the rate of reaction, whilst preventing catalyst deactivation over time. The maximum examined value, 4 equiv, provided almost double the level of conversion, versus conditions in the absence of water (38\% vs $73 \%$, see Supporting Information section 2.2.6.).

These CSMs use $\mathrm{Al}_{2} \mathrm{O}_{3}$ as a catalyst support material, so there were concerns over their stability under aqueous conditions. To ensure that this would not cause catalyst degradation, one single CSM was exposed to an increasing quantity of water from 4 to 512 equiv in a control experiment (512 equiv corresponds to a THF:water volumetric ratio of $2: 1.9)$. Surprisingly, no loss of activity or visible degradation was observed. Furthermore, inductively coupled plasma mass spectrometry (ICP-MS) analysis of the reactor effluent showed no elevated levels of palladium, indicating that the CSMs were stable, even in the presence of such high levels of water (see Supporting Information section 2.1.). Accordingly, experiments were continued without concern for the effect of water on CSM stability.

The reaction concentration was also examined, using the twopump setup (see Supporting Information section 2.2.3.). This demonstrated that it would be possible to reach higher throughput and minimize solvent waste by operating at higher concentration. However, with the solubility of $\mathbf{2}$ and $\mathbf{3}$ in mind, it was decided that $0.4 \mathrm{M}$ would provide good experimental results, as a basis for further optimization and minimization of deactivation, whilst mitigating the risks of starting material or product precipitation in the process.

Using this reaction setup, it was possible to rapidly screen reaction parameters within each experimental run. This was exploited in two separate experiments, each examining nine experimental conditions (Figure 4a shows the results of one such experiment). A clear trend was observed, in which higher temperature and higher $\mathrm{H}_{2} \mathrm{O}$ loading improved conversion. In the second of these experiment sets, jacket temperature was varied in the same manner, as well as varying the pressure from 10 to 30 bar (see Supporting Information section 2.2.8.), where pressure showed only a minor effect.

From these experiments ( 25 in total, including 2 repetitions) it was possible to build a model (using Sartorius Modde v12.1 software) representing the most significant reaction variables. As anticipated by qualitative observations, the temperature was by far the most significant parameter, followed by $\mathrm{H}_{2} \mathrm{O}$ loading. Conversely, reaction pressure had a relatively minimal effect. A contour plot representing predictions of conversion at different conditions could be plotted from this data (Figure $\mathbf{4 b}$ ).
Figure 4. Real-time Analysis of Detailed Parameter Screening Experiments

(a)

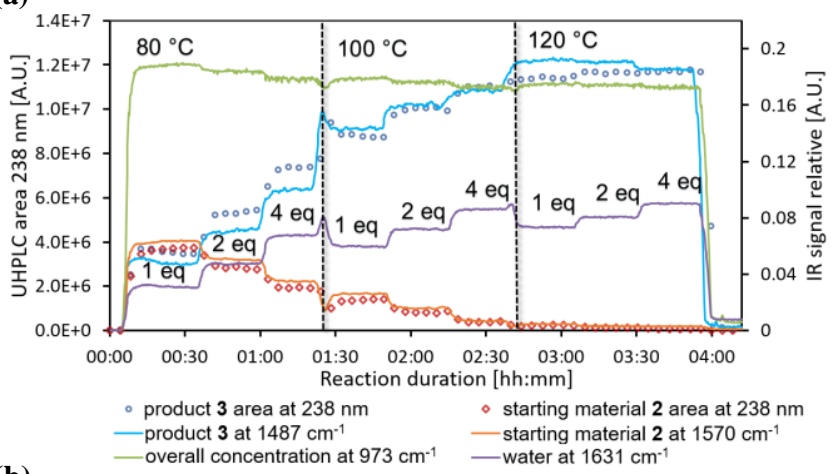

(b)

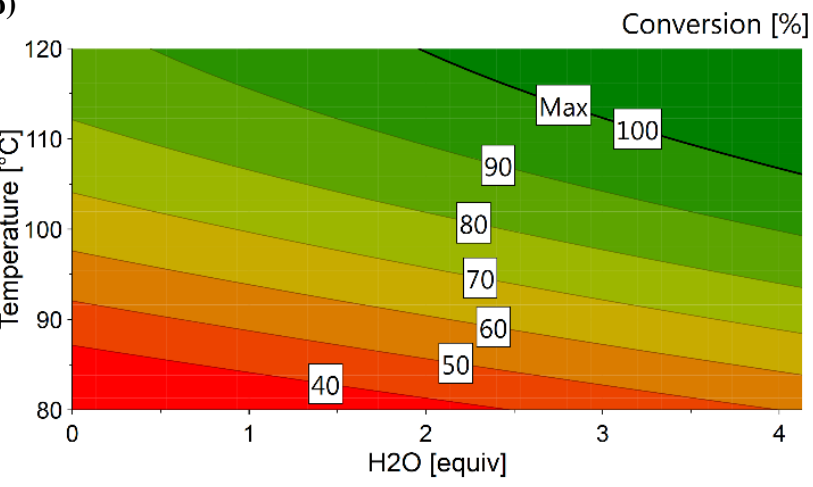

(a) Detailed parameter screening, monitored by FT-IR (colored lines, every $15 \mathrm{~s}$ ) and UHPLC (colored points, every $4.25 \mathrm{~min}$ ). Concentration $=0.4 \mathrm{M}$, liquid flow rate $=2 \mathrm{~mL} / \mathrm{min}$, pressure $=20$ bar. (b) Contour plot built using data from optimization experiments, showing the conversion of starting material $\mathbf{2}$ as a function of the two most influential reaction parameters: jacket temperature and quantity of added $\mathrm{H}_{2} \mathrm{O}$.

Separately, an experiment demonstrated that the flow rate of $\mathrm{H}_{2}$ had no effect on reaction performance, so long as sufficient $\mathrm{H}_{2}$ is supplied (see Supporting Information 2.3.2.). As observed in previous studies using this reactor system, ${ }^{13}$ the residence time is not affected by excess gas, likely due to a stratified flow regime within the reactor. Based on the knowledge gained in these experiments, the jacket temperature, pressure, $\mathrm{H}_{2}$ equiv were set at $120{ }^{\circ} \mathrm{C}, 20$ bar and 3.3 equiv (10\% excess), respectively, for all following experiments. The entire initial optimization campaign was performed using the same 4 CSMs, which showed no signs of irreversible deactivation over this period.

\section{Further Optimization and Stability Demonstration (8 CSMs)}

Based on the lessons learnt in the previous experiments using $4 \mathrm{CSMs}$, further experiments were performed with $8 \mathrm{CSMs}$, to begin to determine the level of throughput that could be reached in this reaction system. Key to this experiment was the quantity of key impurities $(\mathbf{4}+\mathbf{5}$ and $\mathbf{6})$ observed with increasing flow rate. It had already been determined that a higher flow rate would result in increased levels of these impurities, due to shorter residence time, but also that adding water to the input solution would decrease them. Accordingly, an array of conditions were examined, in which the flow rate and water content were varied (Table 1). 
Table 1. Offline UHPLC Results for Experiments to Determine Possible Throughput Using 8 CSMs

\begin{tabular}{ccccccc}
\hline $\begin{array}{c}\text { Entry } \\
\end{array}$ & $\begin{array}{c}\text { Flow rate } \\
{[\mathrm{mL} / \mathrm{min}]}\end{array}$ & $\begin{array}{c}\mathrm{H}_{2} \mathrm{O} \\
{[\text { equiv] }}\end{array}$ & $\begin{array}{c}\mathbf{3} \\
\text { [area\%] }\end{array}$ & $\begin{array}{c}\mathbf{2} \\
\text { [area\%] }\end{array}$ & $\begin{array}{c}\mathbf{4 + 5} \\
{[\text { area\%] }}\end{array}$ & $\begin{array}{c}\mathbf{6} \\
{[\text { area\%] }}\end{array}$ \\
\hline 1 & 4.0 & 2.0 & 98.682 & $<$ r.l. & 0.083 & 0.053 \\
2 & 4.0 & 4.0 & 99.022 & $<$ r.l. & 0.089 & 0.046 \\
3 & 4.0 & 8.0 & 98.836 & $<$ r.l. & 0.074 & 0.031 \\
\hline 4 & 6.0 & 2.0 & 98.558 & 0.046 & 0.127 & 0.066 \\
5 & 6.0 & 4.0 & 98.558 & 0.028 & 0.110 & 0.047 \\
6 & 6.0 & 8.0 & 98.871 & $<$ r.l. & 0.084 & 0.032 \\
\hline 7 & 8.0 & 2.0 & 97.817 & 0.212 & 0.123 & 0.063 \\
8 & 8.0 & 4.0 & 98.648 & 0.078 & 0.118 & 0.047 \\
9 & 8.0 & 8.0 & 99.104 & $<$ r.l. & 0.091 & 0.033
\end{tabular}

Determined by offline UHPLC analysis. r.l. = reporting limit, set to 0.025 area\%.

Although all results (aside from entry 7) showed very high levels of the desired product $\mathbf{3}(>98.5$ area\%) and essentially no remaining starting material $2(<0.1$ area\%), there was a clear trend observed in the quantity of the key impurities. At low flow rate (entry 1-3) all results showed satisfactory impurity levels, whereas an increased flow rate of $6 \mathrm{~mL} / \mathrm{min}$ (entry 4-6) only provided satisfactory impurity profiles when 8 equiv $\mathrm{H}_{2} \mathrm{O}$ was included in the feed solution. This trend was mirrored in the experiments using $8 \mathrm{~mL} / \mathrm{min}$ flow rate (entry 7-9). These experiments showed that a flow rate of $8 \mathrm{~mL} / \mathrm{min}$ (corresponding to $192 \mathrm{mmol} / \mathrm{h}$ throughput) would be possible, with an acceptable purity profile.

In order to demonstrate the longer-term stability of the reactor system, an experiment was then carried out over two working days: for $10 \mathrm{~h}$, then for $6 \mathrm{~h}$, with solvent washing in between. This demonstration was used to determine the behavior of the reactor, the impurity profile over time and to detect any catalyst leaching or deactivation. The experimental conditions selected for this demonstration were with $8 \mathrm{~mL} / \mathrm{min}$ flow rate, 6 equiv $\mathrm{H}_{2} \mathrm{O}$.

During the course of this experiment, 16 fractions were collection (1 per hour) for detailed offline analysis. Some issues in real-time analysis were observed towards the end of the first day of processing, due to small amounts of precipitation. However, this had no effect on the performance of the reaction itself and no increase in pressure was observed (see Supporting Information section 2.3.4.). Additionally, pumping issues were observed toward the end of the second day of processing, but this was remedied by switching to an alternative pump, resulting in $<5 \mathrm{~min}$ downtime. Gratifyingly, the online analysis (FT-IR and UHPLC) showed no deactivation over the processing time (see Supporting Information section 2.3.4.).

Offline analysis of the fractionated reactor output also provided excellent results. The quantity of product 3 was 99.2 area\% in the first fraction measured and showed no decrease over time - in fact a gradual increase was observed (Figure 5a). Furthermore, starting material $\mathbf{2}$ and key impurities $\mathbf{4}+\mathbf{5}$ and $\mathbf{6}$ were low in the first fraction and decreased over time (Figure
$5 \mathbf{b})$. None of the collected fractions provided $>0.1$ area $\%$ of impurities $\mathbf{4}+\mathbf{5}$ combined, or impurity $\mathbf{6}$, meaning that all collected material was within specification.

Figure 5. Reaction Performance over Long Duration Experiment

(a)

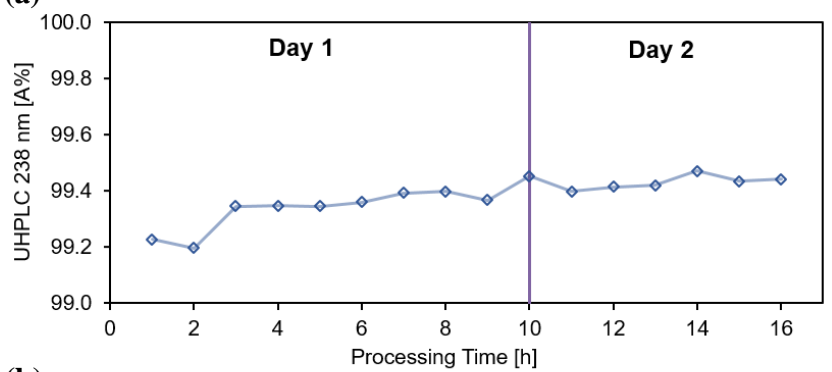

(b)

$\diamond-3$

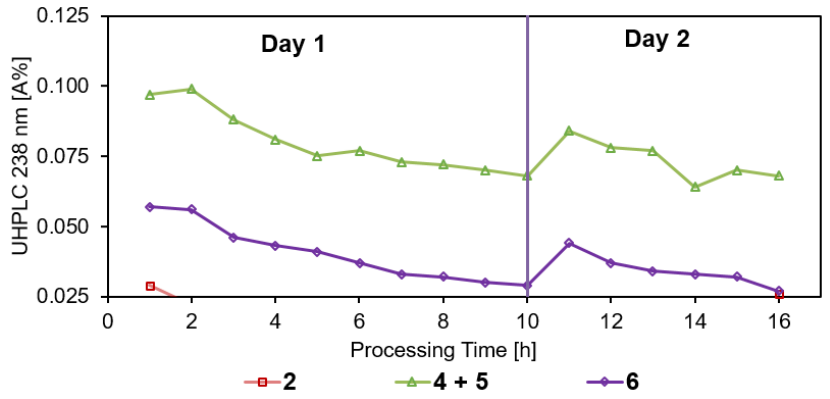

Offline UHPLC measurements of fractionated reactor output are shown. (a) Desired product 3. (b) Starting material 2 and key process intermediates $\mathbf{4 , 5}$ and $\mathbf{6}$. Note: results below reporting limit $(0.025$ area\%) are not shown.

Over this period, $850 \mathrm{~g}(3.07 \mathrm{~mol})$ of starting material was processed, with no loss in catalyst activity over time. Based on a total Pd loading of $96 \mathrm{mg}(0.9 \mathrm{mmol}, 12 \mathrm{mg}$ per CSM), this represents an effective catalyst loading of just 0.011 weight $\%$, which would continue to decrease with longer term processing. When considering the long-term stability of such a process, it is vital to ensure that no leaching of the catalyst is occurring. Accordingly, ICP-MS measurements were carried out on six of the fractions collected and compared with measurements of the

Table 2. ICP-MS Analysis from Long Duration Experiment

\begin{tabular}{cccc}
\hline Entry & Description & Al [ppm] & Pd [ppm] \\
\hline 1 & THF blank $<0.1$ & $<0.001$ \\
2 & THF processed $^{\mathrm{a}}$ & $<0.1$ & $0.005 \pm 0.001$ \\
3 & Reaction mixture $<0.1$ & $1.315 \pm 0.015$ \\
\hline 4 & Day 1, 1h & $<0.1$ & $0.120 \pm 0.002$ \\
5 & Day 1, 6 h & $<0.1$ & $0.120 \pm 0.002$ \\
6 & Day 1, 10 h & $<0.1$ & $0.106 \pm 0.006$ \\
\hline 7 & Day 2, 1 h & $<0.1$ & $0.134 \pm 0.002$ \\
8 & Day 2, 4 h & $<0.1$ & $0.106 \pm 0.004$ \\
9 & Day 2, 6 h & $<0.1$ & $0.104 \pm 0.002$ \\
\hline
\end{tabular}

aTHF solvent, which had been passed through the reactor under the set conditions $\left(120^{\circ} \mathrm{C}, 20\right.$ bar, with $\mathrm{H}_{2}$ flow). 
input reaction mixture and solvent blanks (Table 2). No detectable level of $\mathrm{Al}$ was observed in any samples, implying that there was no degradation of the alumina support over time, in agreement with previous work using this type of CSM. ${ }^{13}$

The input reaction solution was found to contain $1.315 \pm 0.015 \mathrm{ppm}$ of $\mathrm{Pd}$, due to a Buchwald-Hartwig amination in the preparation of $2 .{ }^{3}$ However, to our surprise, the reactor effluent contained significantly less $\mathrm{Pd}$, consistently in the range of $0.1 \mathrm{ppm}$. This was attributed to the ability of alumina to scavenge some quantity of $\mathrm{Pd}$ from the reaction solution and could explain the improvement in performance over the duration of the experiment (Figure 5b). However, it should be noted that the quantity of Pd introduced in this manner likely does not have a significant impact upon the successful reaction operation overall, since its adsorption/deposition in this manner is unlikely to result in catalytically active surface.

\section{Maximum Throughput Processing (16 CSMs)}

It was noted that the increase in possible throughput from 4 to $8 \mathrm{CSMs}$ was higher than an expected linear scale up ( $48 \mathrm{mmol} / \mathrm{h}$ to $192 \mathrm{mmol} / \mathrm{h}$; a four-fold increase). This is reasoned to be caused by improved mixing, which is achieved at higher flow rates, but may also be influenced by minor temperature increase due to reaction exotherm. Accordingly, it was decided that an additional demonstration of the reactor at its full capacity of 16 CSMs would be of interest, to determine the maximum reachable productivity in this reactor system. In order to manage significantly higher flow rates, the reactor system underwent some minor modifications including adding a heat exchanger prior to the reactor and implementing four

\section{Figure 6. Real-time Analysis of High Throughput Experiment Using 16 CSMs}

(a)
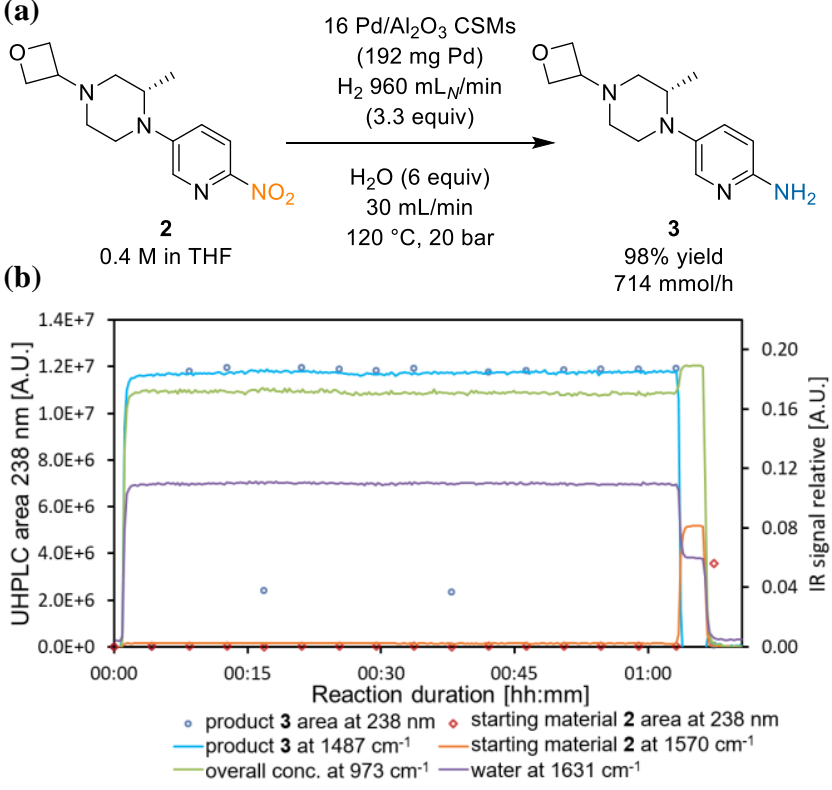

(a) Reaction scheme showing the reaction conditions for maximum throughput: $714 \mathrm{mmol} / \mathrm{h}$ using $16 \mathrm{CSMs}$. (b) Online monitoring of high-throughput experiment by FT-IR (colored lines, every $15 \mathrm{~s}$ ) and UHPLC (colored points, every $4.25 \mathrm{~min}$ ). Concentration = $0.4 \mathrm{M}$, pressure $=20 \mathrm{bar}$, jacket temperature $=120{ }^{\circ} \mathrm{C}$, liquid flow rate $=30 \mathrm{~mL} / \mathrm{min}$. Note: two UHPLC samples $(17$ and $38 \mathrm{~min})$ provided erroneous results, due to an injection error. additional internal temperature sensors inside the reactor itself (between fluidic channels).

An initial screening experiment examined the reaction performance at $16 \mathrm{~mL}$ (according to linear scalability from the 8 CSM setup) as well as 20, 24, 27 and $30 \mathrm{~mL} / \mathrm{min}$. Surprisingly, an excellent impurity profile was observed, even at $30 \mathrm{~mL} / \mathrm{min}$, with acceptable levels of $\mathbf{4}+\mathbf{5}(0.082$ area\%) and an exceptionally low level of $6(0.039$ area\%). These conditions were then run for $1 \mathrm{~h}$, to ensure stability and process a larger quantity of material (Figure 6).

The outstanding throughput achieved in this experiment represents a remarkable improvement compared to the expected value (Figure 7). This corresponds to an increasing space-time yield with scale-up, likely due to improved mixing with higher flow rates. ${ }^{16}$ The maximum space-time yield achieved here is $26.2 \mathrm{~mol} / \mathrm{L} / \mathrm{h}$, owing to the small reactor channels used (27.2 $\mathrm{mL}$ void volume).

Figure 7. Comparison of Throughput with Increasing Number of CSMs

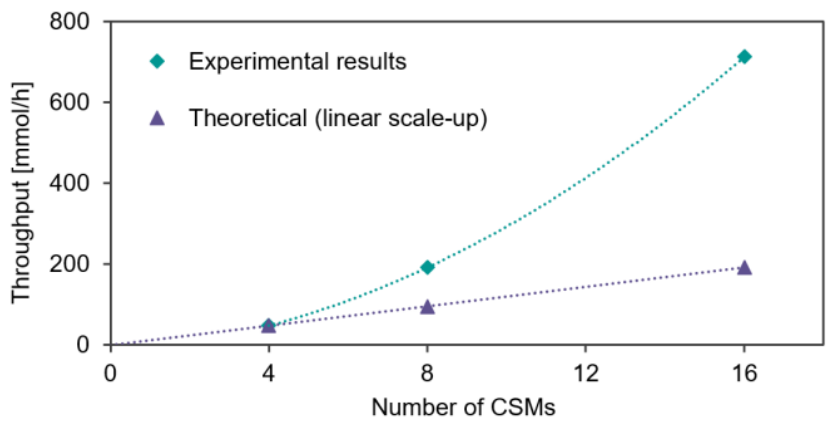

Experimental throughput achieved, compared to the theoretical value, linearly extrapolated from initial reactions using 4 CSMs.

With a view to further scale-up toward production scale, the CSM approach offers a straightforward solution. ${ }^{17}$ The negligible pressure drop in this system means that the reactor length and number of parallel channels can be increased, numbering up the quantity of CSMs substantially before becoming problematic. ${ }^{14}$ In this manner, the exact same CSMs can be used, maintaining the same active surface area, pore size and other critical catalyst parameters. This relieves a substantial hurdle in the development of standard heterogeneously catalyzed process, wherein the catalyst size/properties must often be changed to operate at different reaction scales.

When operating at high throughput, a notable internal temperature rise was observed $\left(\sim 12^{\circ} \mathrm{C}\right)$, especially in the first reaction channel, due to the reaction exotherm (see Supporting Information section 2.4.1.). This study benefited greatly from the additional temperature sensors in the reaction channel, which allowed the behavior over the progress of the reaction to be monitored. For larger scale operation, this exotherm could be managed by a variety of approaches, such as alternating CSMs with inactive static mixers, or introducing substoichiometric quantities of $\mathrm{H}_{2}$ at multiple positions along the reactor. 


\section{CONCLUSION}

In conclusion, $\mathrm{Pd} / \mathrm{Al}_{2} \mathrm{O}_{3} \mathrm{CSM}$ s have been demonstrated as an industrially viable technology for an aromatic nitro reduction in the synthesis of fenebrutinib. Problematic catalyst deactivation was understood and tackled with the assistance of real-time analysis, leading to a simple solution of higher temperature operation and addition of small quantities of water. This realtime analysis also enabled rapid optimization of reaction parameters, in a data-rich environment, with a total of $72 \mathrm{~h} \mathrm{FT-}$ IR data and $>1100$ online UHPLC samples measured. In addition, detailed offline analysis was used to confirm the impurity profile in each case.

The optimized parameters were applied to a system with 8 CSMs, where the throughput could be increased to a higherthan-anticipated level. Importantly, the reaction could be operated for a $16 \mathrm{~h}$ period $(10 \mathrm{~h}+6 \mathrm{~h}$ over 2 days), with no deactivation or leaching observed. Finally, moving to 16 CSMs facilitated an exceptional throughput of $714 \mathrm{mmol} / \mathrm{h}$ (spacetime yield $=26.2 \mathrm{~mol} / \mathrm{L} / \mathrm{h}$ or $6.5 \mathrm{~kg} / \mathrm{L} / \mathrm{h}$ ). When combined with a straightforward scale-up strategy and good control over impurities, this represents a breakthrough application in pharmaceutical processing.

\section{ASSOCIATED CONTENT}

Supporting Information. This material is available free of charge via the Internet at http://pubs.acs.org.

Further details of reaction setups, experimental results and NMR data (PDF)

\section{AUTHOR INFORMATION}

\section{Corresponding Author}

* Email: jason.williams@ @rcpe.at, oliver.kappe@uni-graz.at

\section{Funding Sources}

The CC FLOW Project (Austrian Research Promotion Agency FFG No. 862766) is funded through the Austrian COMET Program by the Austrian Federal Ministry for Climate Protection, Environment, Energy, Mobility, Innovation and Technology (BMK), the Austrian Federal Ministry for Digital and Economic Affairs (BMDW), and by the State of Styria (Styrian Funding Agency SFG). The INFRA FLOW project (Zukunftsfonds Steiermark No. 9003) is funded by the State of Styria (Styrian Funding Agency SFG)

\section{ACKNOWLEDGMENT}

The authors thank Prof. Walter Goessler (University of Graz) for ICP-MS analysis. In addition, Dr. David Linder, Dr. Helena Reymond and Dr. Lukas Chytil (Roche) are acknowledged for their valuable input to the project, as well as Dr. Christian Hornung (CSIRO) for helpful discussion on CSM technology.

\section{ABBREVIATIONS}

API, active pharmaceutical ingredient; BPR, back pressure regulator; BTK, Bruton's tyrosine kinsase; CSM, catalytic static mixer; ICP-MS, inductively coupled plasma mass spectrometry; MS, multiple sclerosis.

\section{REFERENCES}

(1) (a) Freedman, M. S. Disease-Modifying Drugs for Multiple Sclerosis: Current and Future Aspects. Expert Opin. Pharmacother. 2006,
7, 1-9; (b) Frohman, E. M.; Racke, M. K.; Raine, C. S. Multiple Sclerosis — The Plaque and Its Pathogenesis. N. Engl. J. Med. 2006, 354, 942-955; (c) Noseworthy, J. H.; Luncchinetti, C.; Rodriguez, M.; Weinshenker, B. G. Clinical Course and Diagnosis. N. Engl. J. Med. 2000, 343, 938-952.

(2) Crawford, J. J.; Johnson, A. R.; Misner, D. L.; Belmont, L. D.; Castanedo, G.; Choy, R.; Coraggio, M.; Dong, L.; Eigenbrot, C.; Erickson, R.; et al. Discovery of GDC-0853: A Potent, Selective, and Noncovalent Bruton's Tyrosine Kinase Inhibitor in Early Clinical Development. J. Med. Chem. 2018, 61, 2227-2245.

(3) Zhang, H.; Cravillion, T.; Lim, N. K.; Tian, Q.; Beaudry, D.; Defreese, J. L.; Fettes, A.; James, P.; Linder, D.; Malhotra, S.; Han, C.; Angelaud, R.; Gosselin, F. Development of an Efficient Manufacturing Process for Reversible Bruton's Tyrosine Kinase Inhibitor GDC-0853. Org. Process Res. Dev. 2018, 22, 978-990.

(4) For selected reviews on scaling up gas-liquid processes, see: (a) Duduković, M. P.; Mills, P. L. Scale-up and Multiphase Reaction Engineering. Curr. Opin. Chem. Eng. 2015, 9, 49-58; (b) Dudukovic, M. P. Frontiers in Reactor Engineering. Science 2009, 325, 698-701; (c) Mills, P. L.; Chaudhari, R. V. Multiphase Catalytic Reactor Engineering and Design for Pharmaceuticals and Fine Chemicals. Catal. Today 1997, 37, 367-404; (d) Chaudhari, R. V.; Mills, P. L. Multiphase Catalysis and Reaction Engineering for Emerging Pharmaceutical Processes. Chem. Eng. Sci. 2004, 59, 5337-5344.

(5) (a) Stoessel, F. Experimental Study of Thermal Hazards during the Hydrogenation of Aromatic Nitro Compounds. J. Loss Prev. Process Ind. 1993, 6, 79-85; (b) Figueras, F.; Coq, B. Hydrogenation and Hydrogenolysis of Nitro-, Nitroso-, Azo-, Azoxy- and Other NitrogenContaining Compounds on Palladium. J. Mol. Catal. A Chem. 2001, 173, 223-230; (c) Visentin, F.; Puxty, G.; Kut, O. M.; Hungerbühler, K. Study of the Hydrogenation of Selected Nitro Compounds by Simultaneous Measurements of Calorimetric, FT-IR, and Gas-Uptake Signals. Ind. Eng. Chem. Res. 2006, 45, 4544-4553.

(6) For selected reviews featuring hydrogenation reactions in continuous flow, see: (a) Tanimu, A.; Jaenicke, S.; Alhooshani, K. Heterogeneous Catalysis in Continuous Flow Microreactors: A Review of Methods and Applications. Chem. Eng. J. 2017, 327, 792-821; (b) Cossar, P. J.; Hizartzidis, L.; Simone, M. I.; McCluskey, A.; Gordon, C. P. The Expanding Utility of Continuous Flow Hydrogenation. Org. Biomol. Chem. 2015, 13, 7119-7130. (c) Irfan, M.; Glasnov, T. N.; Kappe, C. O. Heterogeneous Catalytic Hydrogenation Reactions in Continuous-Flow Reactors. ChemSusChem 2011, 4, 300-316; (d) Plutschack, M. B.; Pieber, B.; Gilmore, K.; Seeberger, P. H. The Hitchhiker's Guide to Flow Chemistry. Chem. Rev. 2017, 117, 11796-11893; (e) Kiwi-Minsker, L.; Renken, A. Microstructured Reactors for Catalytic Reactions. Catal. Today 2005, 110, 2-14; (f) Mallia, C. J.; Baxendale, I. R. The Use of Gases in Flow Synthesis. Org. Process Res. Dev. 2016, 20, 327-360; (g) Hessel, V.; Angeli, P.; Gavriilidis, A.; Löwe, H. Gas-Liquid and Gas-Liquid-Solid Microstructured Reactors: Contacting Principles and Applications. Ind. Eng. Chem. Res. 2005, 44, 9750-9769; (h) Gutmann, B.; Cantillo, D.; Kappe, C. O. Continuous-Flow Technology - A Tool for the Safe Manufacturing of Active Pharmaceutical Ingredients. Angew. Chem. Int. Ed. 2015, 54, 6688-6728.

(7) For selected reviews of packed bed reactors, see: (a) Al-Dahhan, M. H.; Larachi, F.; Dudukovic, M. P.; Laurent, A. High-Pressure TrickleBed Reactors: A Review. Ind. Eng. Chem. Res. 1997, 36, 3292-3314; (b) Herskowitz, M.; Smith, J. M. Trickle-Bed Reactors: A Review. AIChE J. 1983, 29, 1-18.

(8) (a) Loos, P.; Alex, H.; Hassfeld, J.; Lovis, K.; Platzek, J.; Steinfeldt, N.; Hübner, S. Selective Hydrogenation of Halogenated Nitroaromatics to Haloanilines in Batch and Flow. Org. Process Res. Dev. 2016, 20, 452-464; (b) Cantillo, D.; Damm, M.; Dallinger, D.; Bauser, M.; Berger, M.; Kappe, C. O. Sequential Nitration/Hydrogenation Protocol for the Synthesis of Triaminophloroglucinol: Safe Generation and Use of an Explosive Intermediate under Continuous-Flow Conditions. Org. Process Res. Dev. 2014, 18, 1360-1366; (c) Duan, S.; Feng, X.; Gonzalez, M.; Bader, S.; Hayward, C.; Ljubicic, T.; Lu, J.; Mustakis, J.; Maloney, M.; Rainville, J.; Zhang, X. Developing a Multistep Continuous Manufacturing Process for (1R,2R)-2-Amino-1-methylcyclopentan-1-ol. Org. Process Res. Dev. 2020, 24, 2734-2744; (d) Cole, K. P.; Reizman, B. J.; Hess, M.; Groh, J. M.; Laurila, M. E.; Cope, R. F.; Campbell, B. M.; Forst, M. B.; Burt, J. L.; Maloney, T. D.; et al. Small-Volume Continuous Manufacturing of Merestinib. Part 1. Process Development and Demonstration. Org. Process Res. Dev. 2019, 23, 858-869; (e) Said, M. Ben; Baramov, T.; Herrmann, T.; Gottfried, M.; Hassfeld, J.; Roggan, S. Continuous Selective Hydrogenation of Refametinib Iodo-Nitroaniline Key Intermediate DIM- 
NA over Raney Cobalt Catalyst at Kg/Day Scale with Online UV-Visible Conversion Control. Org. Process Res. Dev. 2017, 21, 705-714; (f) Ouchi, T.; Battilocchio, C.; Hawkins, J. M.; Ley, S. V. Process Intensification for the Continuous Flow Hydrogenation of Ethyl Nicotinate. Org. Process Res. Dev. 2014, 18, 1560-1566; (g) Tu, J.; Sang, L.; Cheng, H.; Ai, N.; Zhang, $\mathrm{J}$. Continuous Hydrogenolysis of $N$-Diphenylmethyl Groups in a Micropacked-Bed Reactor. Org. Process Res. Dev. 2020, 24, 59-66.

(9) (a) Yang, C.; Teixeira, A. R.; Shi, Y.; Born, S. C.; Lin, H.; Li Song, Y.; Martin, B.; Schenkel, B.; Peer Lachegurabi, M.; Jensen, K. F. Catalytic Hydrogenation of: N -4-Nitrophenyl Nicotinamide in a MicroPacked Bed Reactor. Green Chem. 2018, 20, 886-893; (b) Carangio, A.; Edwards, L. J.; Fernandez-Puertas, E.; Hayes, J. F.; Kucharski, M. M.; Rutherford, G. W.; Wheelhouse, K. M. P.; Williams, G. D. Evaluation of Sponge Metal Catalysts in a Trickle Bed Reactor for the Continuous Hydrogenation of an Aliphatic Nitro Intermediate. Org. Process Res. Dev. 2020, 24, 1909-1915.

(10) (a) Tourvieille, J. N.; Philippe, R.; de Bellefon, C. Milli-Channel with Metal Foams under an Applied Gas-Liquid Periodic Flow: External Mass Transfer Performance and Pressure Drop. Chem. Eng. J. 2015, 267, 332-346; (b) Lévêque, J.; Philippe, R.; Zanota, M. L.; Meille, V.; Sarrazin, F.; Baussaron, L.; de Bellefon, C. Hydrodynamics and Mass Transfer in a Tubular Reactor Containing Foam Packings for Intensification of G-L-S Catalytic Reactions in Co-Current up-Flow Configuration. Chem. Eng. Res. Des. 2016, 109, 686-697; (c) Verho, O.; Gustafson, K. P. J.; Nagendiran, A.; Tai, C. W.; Bäckvall, J. E. Mild and Selective Hydrogenation of Nitro Compounds Using Palladium Nanoparticles Supported on AminoFunctionalized Mesocellular Foam. ChemCatChem 2014, 6, 3153-3159; (d) Tourvieille, J. N.; Philippe, R.; de Bellefon, C. Milli-Channel with Metal Foams under an Applied Gas-Liquid Periodic Flow: Flow Patterns, Residence Time Distribution and Pulsing Properties. Chem. Eng. Sci. 2015, $126,406-426$

(11) (a) Fernandez-Puertas, E.; Robinson, A. J.; Robinson, H.; Sathiyalingam, S.; Stubbs, H.; Edwards, L. J. Evaluation and Screening of Spherical $\mathrm{Pd} / \mathrm{C}$ for Use as a Catalyst in Pharmaceutical-Scale Continuous Hydrogenations. Org. Process Res. Dev. 2020, 24, 2147-2156; (b) Klefer, H.; Munoz, M.; Modrow, A.; Böhringer, B.; Wasserscheid, P.; Etzold, B. J. M. Polymer-Based Spherical Activated Carbon as Easy-to-Handle Catalyst Support for Hydrogenation Reactions. Chem. Eng. Technol. 2016, 39, 276 284; (c) Garcia-Olmo, A. J.; Yepez, A.; Balu, A. M.; Romero, A. A.; Li, Y.; Luque, R. Insights into the Activity, Selectivity and Stability of Heterogeneous Catalysts in the Continuous Flow Hydroconversion of Furfural. Catal. Sci. Technol. 2016, 6, 4705-4711.

(12) (a) Gardiner, J.; Nguyen, X.; Genet, C.; Horne, M. D.; Hornung, C. H.; Tsanaktsidis, J. Catalytic Static Mixers for the Continuous Flow Hydrogenation of a Key Intermediate of Linezolid (Zyvox). Org. Process Res. Dev. 2018, 22, 1448-1452; (b) Avril, A.; Hornung, C. H.; Urban, A.; Fraser, D.; Horne, M.; Veder, J.-P.; Tsanaktsidis, J.; Rodopoulos, T.; Henry, C.; Gunasegaram, D. R. Continuous Flow Hydrogenations Using Novel Catalytic Static Mixers inside a Tubular Reactor. React. Chem. Eng. 2017, 2, 180-188; (c) Hornung, C. H.; Nguyen, X.; Carafa, A.; Gardiner, J.; Urban, A.; Fraser, D.; Horne, M. D.; Gunasegaram, D. R.; Tsanaktsidis, J. Use of Catalytic Static Mixers for Continuous Flow Gas-Liquid and Transfer Hydrogenations in Organic Synthesis. Org. Process Res. Dev 2017, 21, 1311-1319; (d) Kundra, M.; Grall, T.; Ng, D.; Xie, Z.; Hornung, C. H. Continuous Flow Hydrogenation of Flavorings and Fragrances Using 3D-Printed Catalytic Static Mixers. Ind. Eng. Chem. Res. 2021.

(13) Lebl, R.; Zhu, Y.; Ng, D.; Hornung, C. H.; Cantillo, D.; Kappe, C. O. Scalable Continuous Flow Hydrogenations Using Pd/A12O3-Coated Rectangular Cross-Section 3D-Printed Static Mixers. Catal. Today 2020 DOI: 10.1016/j.cattod.2020.07.046.

(14) Zhu, Y.; Bin Mohamad Sultan, B.; Nguyen, X.; Hornung, C. Performance Study and Comparison between Catalytic Static Mixer and Packed Bed in Heterogeneous Hydrogenation of Vinyl Acetate. J. Flow Chem. 2021, 10.1007/s41981-021-00152-00157.

(15) For previous use of this experimental and analytical setup, see: (a) Sagmeister, P.; Lebl, R.; Castillo, I.; Rehrl, J.; Kruisz, J.; Sipek, M.; Horn, M.; Sacher, S.; Cantillo, D.; Williams, J. D.; Kappe, C. O. Advanced Real-Time Process Analytics for Multistep Synthesis in Continuous Flow. Angew. Chem. Int. Ed. 2021, 60, 8139-8148; (b) Sagmeister, P.; Williams, J. D.; Hone, C. A.; Kappe, C. O. Laboratory of the Future: A Modular Flow Platform with Multiple Integrated PAT Tools for Multistep Reactions. React. Chem. Eng. 2019, 4, 1571-1578.

(16) For reviews on static mixers, see: (a) Thakur, R. K.; Vial, C.; Nigam, K. D. P.; Nauman, E. B.; Djelveh, G. Static Mixers in the Process Industries - a Review. Chem. Eng. Res. Des. 2003, 81, 787-826; (b)
Ghanem, A.; Lemenand, T.; Della Valle, D.; Peerhossaini, H. Static Mixers: Mechanisms, Applications, and Characterization Methods - A Review. Chem. Eng. Res. Des. 2014, 92, 205-228.

(17) Details on Miprowa reactor and scale-up strategy, Ehrfeld Mikrotechnik, https://ehrfeld.com/en/products/miprowar.html (accessed 04-22-2021). 